\title{
Seropositivity and determinants of immunoglobulin-G (IgG) antibodies against Herpes simplex virus (HSV) types -1 and -2 in pregnant women in Port Harcourt, Nigeria.
}

\author{
Iheanyi Omezuruike Okonko, Tochi Ifeoma Cookey
}

Medical Microbiology Unit, Department of Microbiology, University of Port Harcourt, Nigeria.

\begin{abstract}
Background: This study is the first documented prevalence of IgG antibody against HSV-1\&-2 in Port Harcourt, Nigeria and thus provides baseline data for future in-depth studies on HSV infection in South-South, Nigeria.

Objective: This study determined the seropositivity and determinants of serum IgG antibody against HSV-1 \& HIV-2 among pregnant women attending BMSH, Port Harcourt, Rivers State, Nigeria.

Methods: Serum samples from 180 pregnant women attending antenatal clinic at Braithwaite Memorial Specialist Hospital (BMSH) in Port Harcourt, Nigeria. Serum samples were analysed with commercial HSV type-1\&-2 specific IgG Enzyme Linked Immunosorbent Assay (ELISA) kits. Chi-square analysis was used to determine the association of infection with socio-demographic variables.

Results: Of the 180 pregnant women, 179 (99.4\%) were seropositive and 1(0.6\%) was seronegative for HSV $1 \& 2$ IgG antibody. No statistical association existed between the prevalence of HSV-1\&-2 IgG antibodies and the socio-demographic variables studied $(\mathrm{p}>0.05)$ except for marital status which was significantly associated $(\mathrm{p}<0.05)$.

Conclusion: Our data shows that HSV-1 \& 2 seropositivity among pregnant women in Port Harcourt is high; thus serological screening for HSV-1\&-2 might be advisable for antenatal attendees.

Keywords: BMSH, determinants, ELISA, HSV-1, HSV-2, IgG, seropositivity

DOI: http://dx.doi.org/10.4314/ahs.v15i3.6

Cite as: Okonko IO, Cookey TI. Seropositivity and determinants of immunoglobulin-G (IgG) antibodies against Herpes simplex virus (HSV) types -1 and -2 in pregnant women in Port Harcourt, Nigeria. Afri Health Sci. 2015;15(3):737-47. doi: http://dx.doi.org/10.4314/ahs. $v 15 i 3.6$
\end{abstract}

\section{Introduction}

Amongst the human viral infections all over the world, herpes caused by herpes simplex virus (HSV) types-1 and HSV-2 were the most common ${ }^{1}$. They are one of the most common viral sexually transmitted diseases (STD) worldwide ${ }^{2-3}$ and are now a major public health concern, established by the widespread of genital HSV and heightened acquisition of human immunodeficiency virus (HIV) infections in connotation with HSV acquisition ${ }^{4-5}$.

It has been projected that $90 \%$ of individuals globally remain seropositive for HSV-1 by the fourth decade of

\author{
Corresponding author: \\ Iheanyi Omezuruike Okonko \\ Medical Microbiology Unit, \\ Department of Microbiology, \\ University of Port Harcourt, \\ P.M.B. 5323, Choba, East-West Road, \\ Port Harcourt, Rivers State, Nigeria; \\ E-mail: iheanyi.okonko@uniport.edu.ng, \\ mac2finney@yahoo.com, \\ Tel.: +2348035380891
}

life, particularly persons within low socio-economic levels $^{6}$. An estimate of 536 million people or approximately $16 \%$ of the population of the world in the age group 15-49 years have been shown to be living with HSV-2 worldwide ${ }^{7}$. More women than men have been shown to have acquired the virus ${ }^{7}$. A projection of 315 million females has been reported to be infected with HSV paralleled to an estimate of 221 million infected men 7 The lowest prevalence was found in Western Europe, where prevalence reached a maximum of around $18 \%$ among women and 13\% among men while the highest prevalence was in sub-Saharan Africa, where prevalence reached a maximum of $70 \%$ among women and around $55 \%$ among men ${ }^{7}$.

In order to properly manage herpes patients and develop approaches to avert spread of HSV, efficient serological testing is pertinent. The finding of type-particular antigens in HSV-1 and HSV-2, remarkably IgG antibodies, has remained effectively used to advance tests for the determination of particular HSV antibody [8]. The existence of particular antibodies offers proof of HSV-1, HSV-2, or HSV-1 and HSV-2 ${ }^{8}$. The seropositivity and determinants of IgG antibodies against HSV$1 \&-2$ amongst these pregnant women were examined 
using commercially available enzyme linked immunosobernt assay (ELISA) kits.

\section{Methods}

\section{Study area}

The current study was steered from February 2013 to September, 2013 and was restricted to pregnant women presenting at the antenatal clinic of Braithwaite Memorial Specialist Hospital, Port Harcourt, Nigeria. BMSH is a government owned specialist hospital which is located in the old Government Reserved Area (G.R.A.) of Port Harcourt City. It is a frequently used hospital in Rivers State, which by feature of its setting delivers tertiary health-care services. Port Harcourt lies along the Bonny River in the Niger Delta and it coordinates are $4^{\circ} 53$ '23'N 6 54 ' $18^{\prime \prime} \mathrm{E}$ and located in a city $360 \mathrm{~km} 2$ (139 sq mi).

\section{Study plan}

This is a consecutive hospital based study which was implemented to determine the seropositivity of $\mathrm{IgG}$ antibodies against HSV-1 and HSV-2 amongst pregnant women in Port Harcourt, South South, Nigeria.

\section{Study population}

The targeted populace consist of all the pregnant women presenting at the antenatal clinic of $\mathrm{BMSH}$ from February to September, 2013. A total of 180 consented pregnant women were carefully chosen and registered for the study. The sociodemographic data were collected from their medical registers (Table 1). The information obtained were stratified as follows; the ages of the pregnant women were grouped into four groups- 20-25 years, 26-30 years, 31-35 years and 36-42 years; the marital status was classified as being married or single; the educational status was grouped into primary, secondary, post-secondary and tertiary education while occupational status was grouped as employed, self-employed, unemployed and students. Finally, the gestation periods were classified based on the trimesters the women were in at the time of the study; first, second or third trimesters.

\section{Collection and preparation of samples}

Five milliliters of venous blood were collected into sterile tubes from the enrolled subjects. These samples were centrifuged for 15 minutes and resultant sera were extracted into labelled eppendorf tubes. Sera were stored at temperature of $-20^{\circ} \mathrm{C}$ until use.

\section{Serology}

Sera were examined for IgG antibodies against HSV1 \& HSV-2 using a commercially available ELISA kit manufactured by DIA.PRO Diagnostic Bioprobes Srl Via G. Carducci no 2720099 Sesto San Giovanni, Milano, Italy. These tests were implemented as specified by the manufacturer.

\section{Principle of the test}

The HSV 1\&2 IgG ELISA kit was built on the principle of $\operatorname{IgG}$ capture in which the microplates were coated with native inactivated HSV-1 and HSV-2. The dense stage was mainly treated with the weakened sample and anti-HSV IgG were taken, if existing, by the antigens. Subsequently washing out all the other constituents of the sample. In the second incubation, linked anti-HSV IgG were identified by adding polyclonal specific anti-hIgG antibodies, branded with peroxidase (HRP). The enzyme apprehended on the compacted segment, performing on the substrate/chromogen mix, creates an optical indicator that is proportionate to the quantity of anti-HSV IgG antibodies existing in the sample. A calibration curve plotted alongside a core gold standard, creates potentially, a quantifiable $\operatorname{IgG}$ antibodies determination in the sample. Interpretation of results were done as specified by the manufacturer.

\section{Data analyses}

Outcomes were presented and scrutinised using Statistical Package for Social Sciences (SPSS) 20.0. The seropositivity was considered as the number of samples that tested positive to anti-HSV-1 and HSV-2 IgG antibodies over the number of samples screened multiply by 100 . Chi-square test was employed to define relationships among sociodemographic characteristics of the participants. $\mathrm{P}<0.05$ was set as the statistical significance level.

\section{Results}

\section{Socio-demographic data}

The characteristics of the pregnant women were stratified and presented in Table 1. The median age in the samples was 30.5 years (range, 20 to 42). The age groups; $26-30$ years and $31-35$ years constituted the largest populations making up $40.6 \%(\mathrm{n}=73)$ and $31.7 \%$ $(n=57)$ of the total population respectively, while 30 $(16.7 \%)$ of the pregnant women were aged 20-25years and $20(11.1 \%)$ were aged 36-42 years. Married pregnant women predominated the study constituting $98.3 \%$ of the sample compared to $1.7 \%$ of the population that was single. On the basis of educational background, 
$0.6 \%, 36.7 \%, 6.7 \%$ and $56.1 \%$ of the pregnant women were found to have acquired primary, secondary, post-secondary and tertiary education respectively. A lower percentage of $13.3 \%$ were students and $37.8 \%$ were self employed. While $22.8 \%$ of them were gainfully employed, $26.1 \%$ were unemployed.
Seropositivity of anti-HSV-1\&HSV-2IgGantibodies

From the 180 pregnant women examined, 179 (99.4\%) women were seropositive for anti-HSV-1\& HSV-2 IgG antibodies while $1(0.6 \%)$ was seronegative for anti-HSV-1\& HSV02 IgG antibodies. Table 1 shows the characteristics of the pregnant women tested and their serological outcomes.

Table 1: The characteristics and serological outcomes

\begin{tabular}{|c|c|c|c|c|c|c|c|c|}
\hline \multirow{2}{*}{\multicolumn{2}{|c|}{ Variables }} & \multicolumn{2}{|c|}{ Total } & \multicolumn{4}{|c|}{ HSV-1 \&-2 IgG } & \multirow[t]{3}{*}{ Statistics } \\
\hline & & \multirow{2}{*}{$\begin{array}{l}\text { No. } \\
30\end{array}$} & \multirow{2}{*}{\begin{tabular}{|l|}
$\%$ \\
16.7 \\
\end{tabular}} & \multirow{2}{*}{\begin{tabular}{|c|} 
Positives \\
30
\end{tabular}} & \multirow{2}{*}{\begin{tabular}{|l|}
$\%$ \\
100.0
\end{tabular}} & \multirow{2}{*}{$\frac{\text { Negatives }}{0}$} & \multirow{2}{*}{$\begin{array}{ll}\% & \\
& 0.0\end{array}$} & \\
\hline Age & $20-25$ & & & & & & & \\
\hline & $26-30$ & 73 & 40.6 & 73 & 100.0 & 0 & 0.0 & $\chi^{2}=2.16995$ \\
\hline & $31-35$ & 57 & 31.7 & 56 & 98.2 & 1 & 1.8 & $\mathrm{df}=3, \mathrm{p}>0.05$ \\
\hline & $36-42$ & 20 & 11.1 & 20 & 100.0 & 0 & 0.0 & \\
\hline $\begin{array}{l}\text { Marital } \\
\text { status }\end{array}$ & Married & 177 & 98.3 & 176 & 99.4 & 1 & 0.6 & $x^{2}=0.017$ \\
\hline & Singles & 3 & 1.7 & 3 & 100.0 & 0 & 0.0 & $\mathrm{df}=1, \mathrm{p}<0.05$ \\
\hline Education & Primary & 1 & 0.6 & 1 & 100.0 & 0 & 0.0 & \\
\hline & Secondary & 66 & 36.7 & 66 & 100.0 & 0 & 0.0 & \\
\hline & $\begin{array}{l}\text { Post- } \\
\text { secondary }\end{array}$ & 12 & 6.7 & 12 & 100.0 & 0 & 0.0 & $x^{2}=0.786548$ \\
\hline & Tertiary & 101 & 56.1 & 100 & 99.0 & 1 & 1.0 & $\mathrm{df}=3, \mathrm{p}>0.05$ \\
\hline Occupation & Student & 24 & 13.3 & 24 & 100.0 & 0 & 0.0 & \\
\hline & Unemployed & 47 & 26.1 & 46 & 97.9 & 1 & 2.1 & \\
\hline & $\begin{array}{l}\text { Self- } \\
\text { employed }\end{array}$ & 68 & 37.8 & 68 & 100.0 & 0 & 0.0 & $\chi^{2}=2.8456$ \\
\hline & Employed & 41 & 22.8 & 41 & 100.0 & 0 & 0.0 & $\mathrm{df}=3, \mathrm{p}>0.05$ \\
\hline Gestation & 1st trimester & 28 & 15.6 & 28 & 100.0 & 0 & 0.0 & \\
\hline & $\begin{array}{l}\text { 2nd } \\
\text { trimester }\end{array}$ & 93 & 51.7 & 92 & 98.9 & 1 & 1.1 & $x^{2}=0.94071$, \\
\hline & 3rd trimester & 59 & 32.8 & 59 & 100.0 & 0 & 0.0 & $\mathrm{df}=2, \mathrm{p}>0.05$ \\
\hline Total & & 180 & 100.0 & 179 & 99.4 & 1 & 0.6 & \\
\hline
\end{tabular}


Age-related seropositivity of anti-HSV-1 \& HSV-2 IgG antibodies

The age-related seropositivity of anti-HSV-1 \& HSV-2 $\mathrm{IgG}$ antibodies is presented in Figure 1. Seropositivity of $100.0 \%$ was recorded in $20-25$ years, $26-30$ years and 36-42 years age groups while $98.2 \%$ was found in age group 31-35 years. These differences was not statistically associated $\left(\chi^{2}=2.16995, \mathrm{df}=3, \mathrm{p}>0.05\right)$.

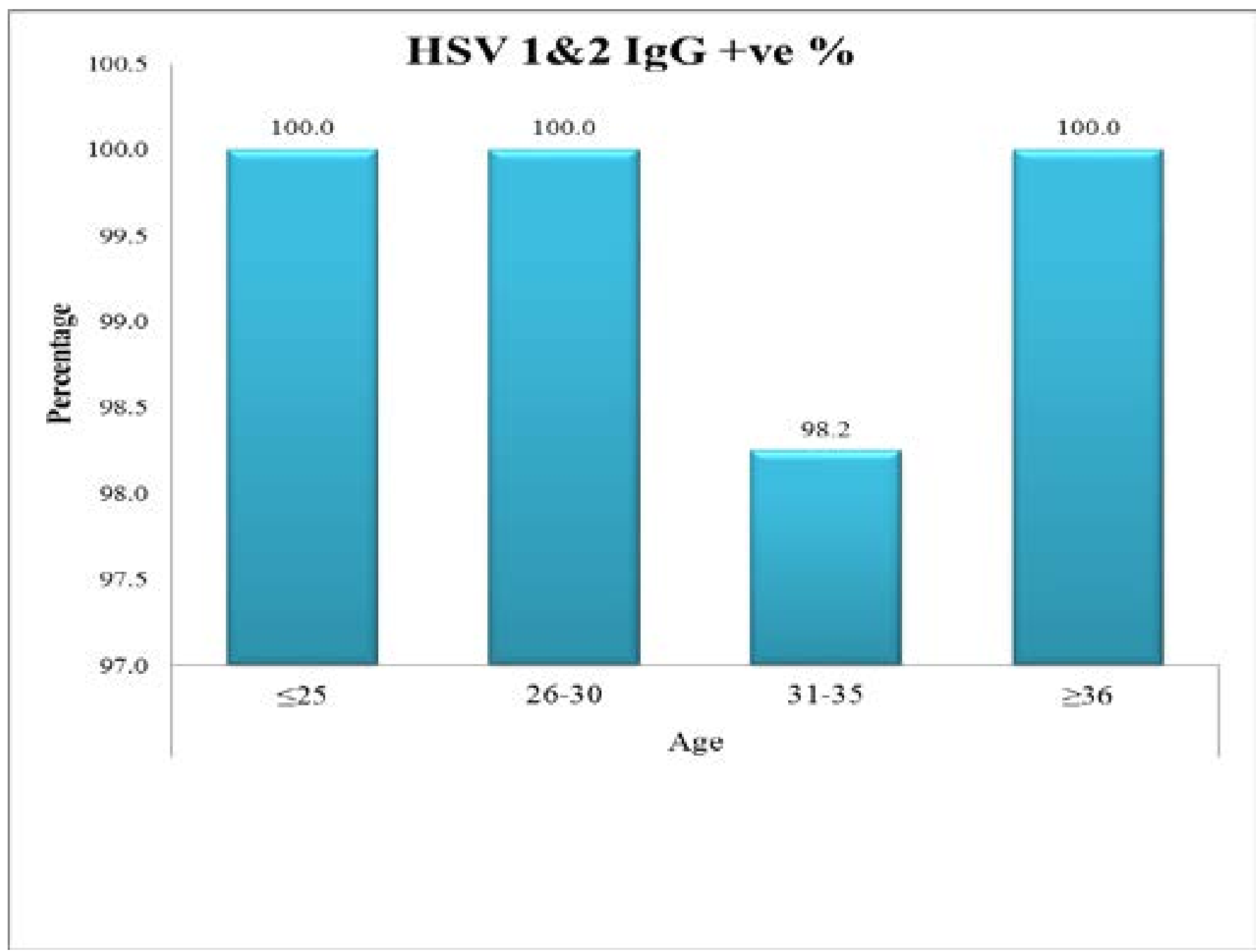

\section{Figure 1: Age-related seropositivity of anti-HSV-1 \& HSV-2 IgG antibodies}

Seropositivity of anti-HSV-1 \& HSV-2 IgG antibodies according to marital status

The seropositivity of anti-HSV-1 \& HSV-2 IgG antibodies in accordance to the marital status is present- ed in Figure 2. The three single pregnant women were found to be seropositive $(100 \%)$ for HSV-1\&2 while 176 married women tested seropositive $(99.4 \%)$. This difference was significantly associated $\left(\chi^{2}=0.017\right.$, $\mathrm{df}=1, \mathrm{p}<0.05)$. 


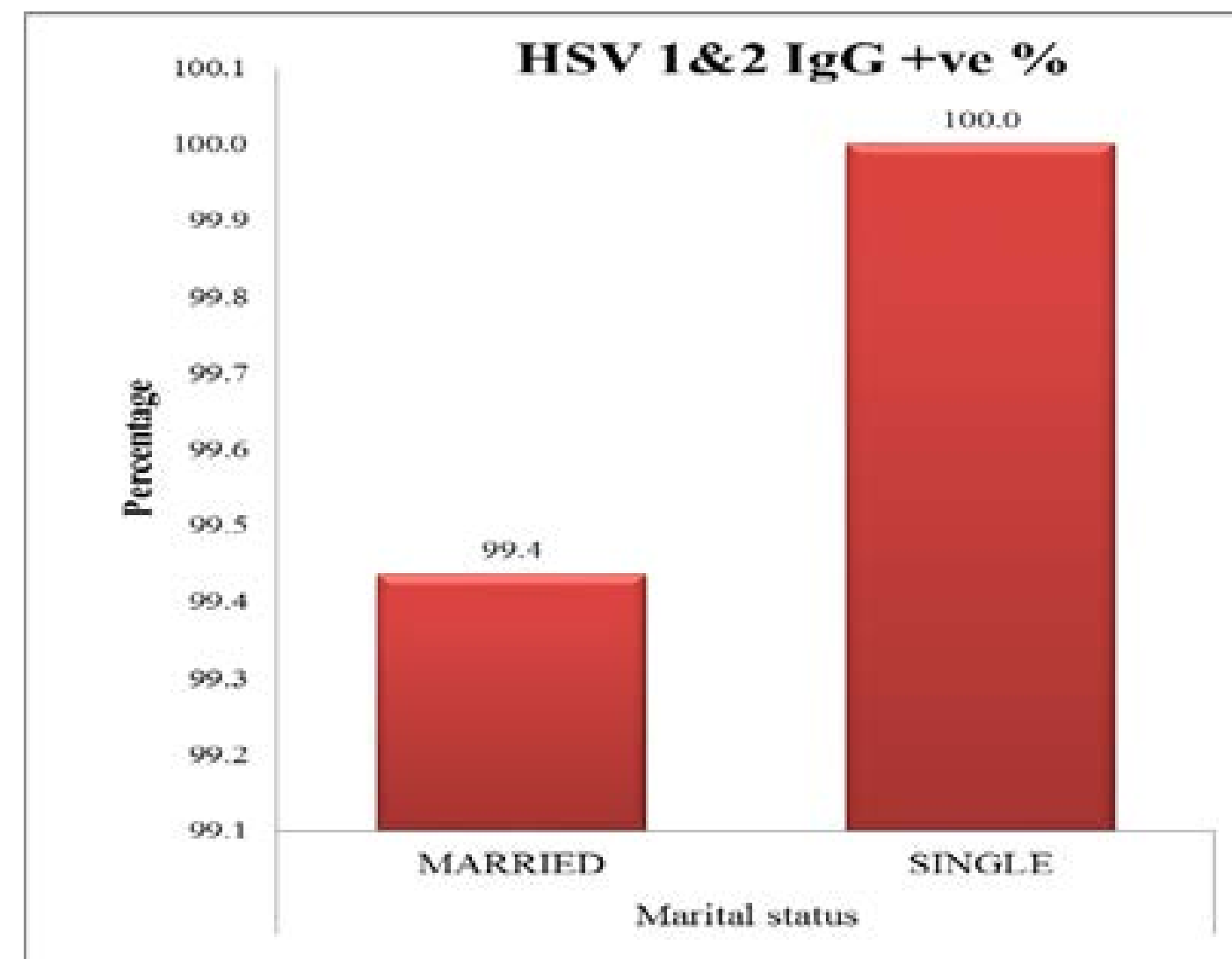

Figure 2: Marital status-related seropositivity of anti-HSV-1 \& HSV-2 IgG antibodies

Seropositivity of anti-HSV-1 \& HSV-2 IgG antibodies in relation to educational background The educational background of these pregnant women showed no significant association with seropositivity of anti-HSV-1 \& HSV-2 IgG antibodies $(\chi 2=0.786548$, $\mathrm{df}=3, \mathrm{p}>0.05)$ as presented in Figure 3. One hundred percent $(100.0 \%)$ of the pregnant women having primary, secondary and post-secondary education had anti-HSV-1 \& HSV-2 IgG antibodies while $99.0 \%$ seropositivity was documented in those with tertiary education (Table 1, Figure 3). 


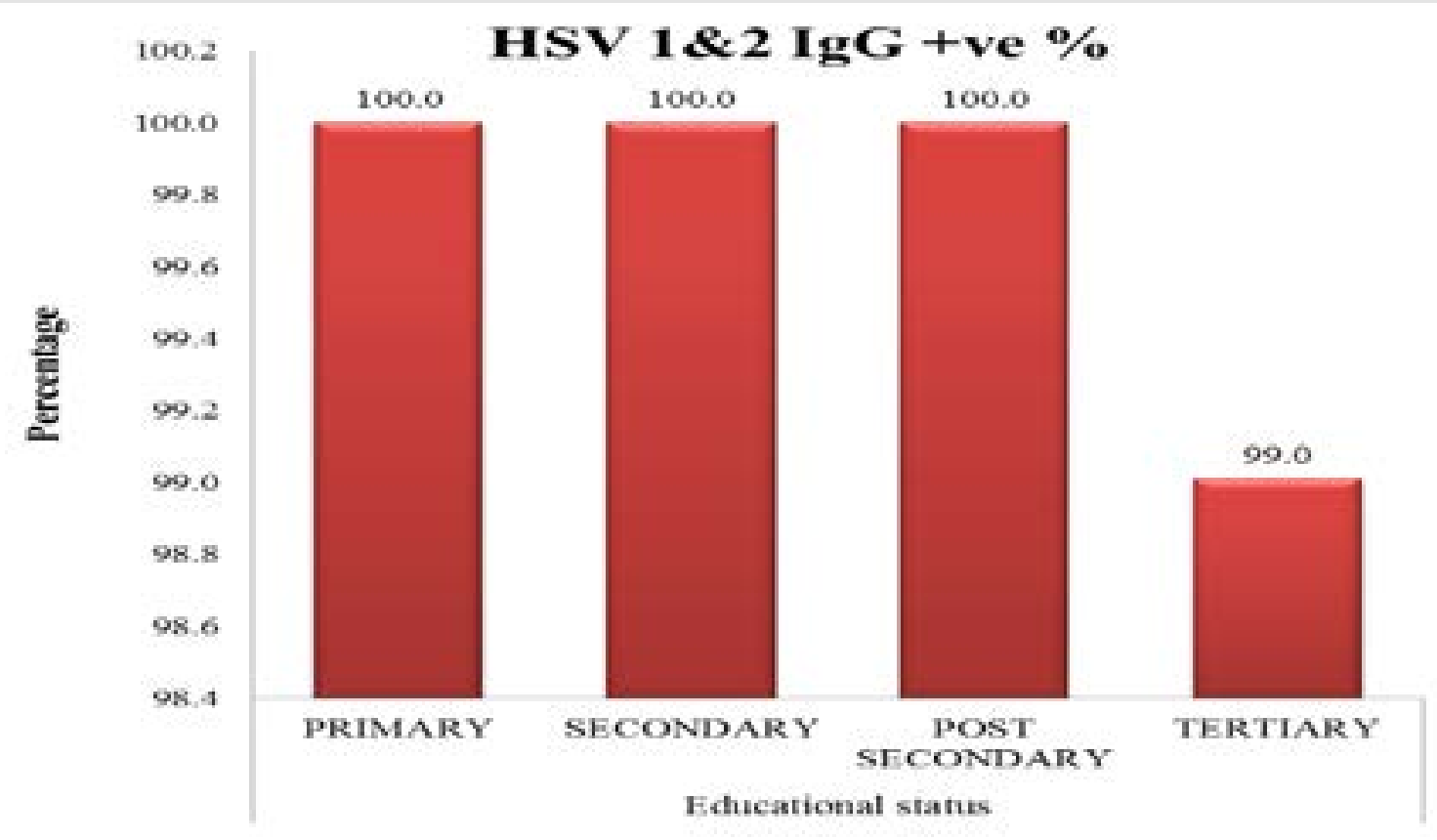

\section{Figure 3: Seropositivity of anti-HSV1 \& HSV-2 IgG antibodies in relation to educational background}

Occupation-related seropositivity of anti-HSV-1 \& HSV-2 IgG antibodies

Occupation-related seropositivity of anti-HSV-1 \& HSV-2 IgG antibodies is presented in Figure 4. The pregnant women that were students, self employed and employed were all seropositive for anti-HSV-1 \& HSV-2 having $100.0 \%$ seropositivity in each group while those that were unemployed had $97.9 \%$ seropositivity (46 of 47). However, these differences were not significantly related $\left(\chi^{2}=2.8456, \mathrm{df}=3, \mathrm{p}>0.05\right)$. 


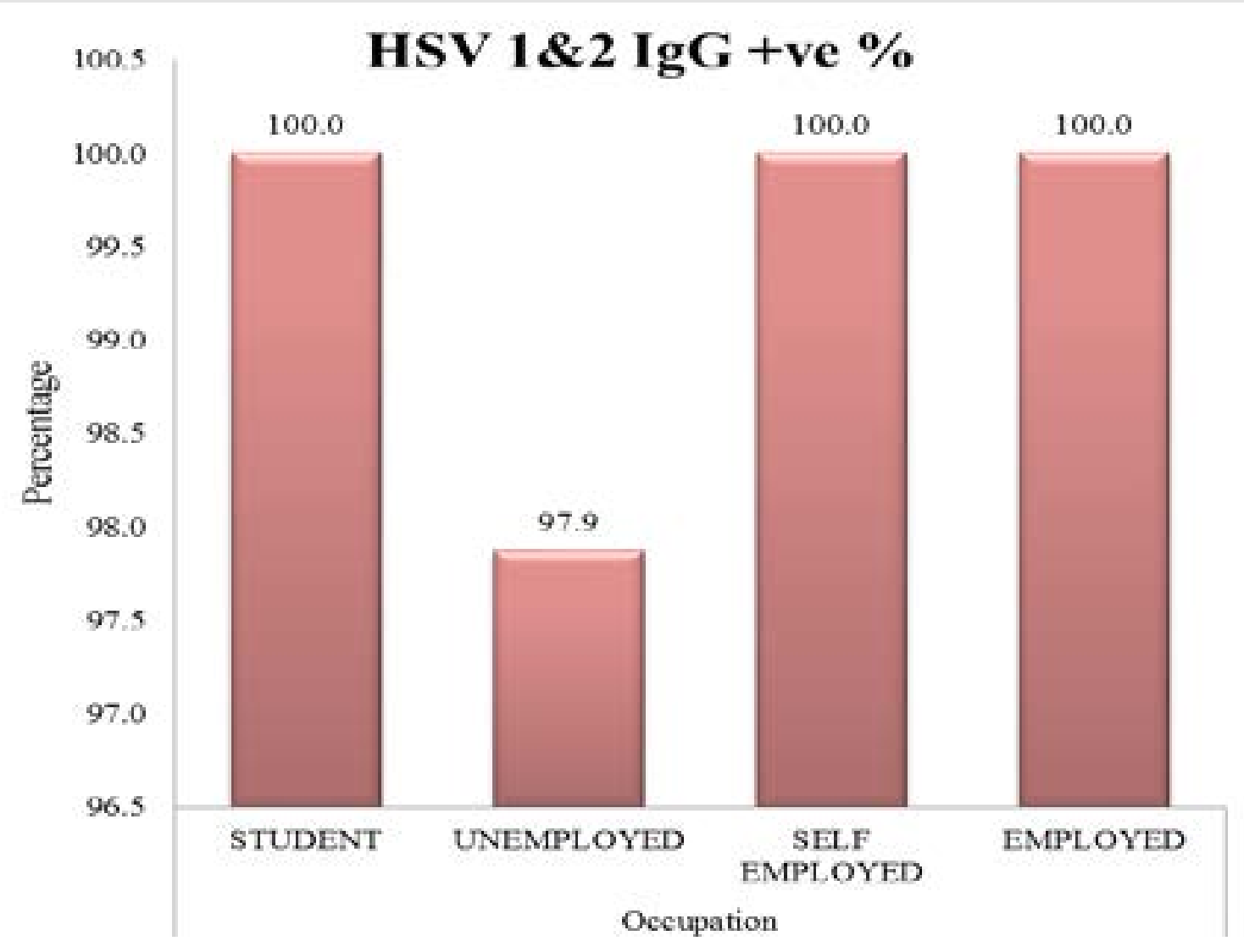

Figure 4: Occupation-related seropositivity of anti-HSV-1 \& HSV-2 IgG antibodies

Seropositivity of anti-HSV-1 \& HSV-2 IgG antibodies in relation to gestation period

Gestation period related seropositivity of anti-HSV-1 \& HSV-2 IgG antibodies is presented in Figure 5. It showed that participants in first and third trimesters had $100.0 \%$ seropositivity compared to those in their second trimester $(98.9 \%)$. Nevertheless, this difference was not significantly associated $(\chi 2=0.94071, \mathrm{df}=2$, $\mathrm{p}>0.05)$. 


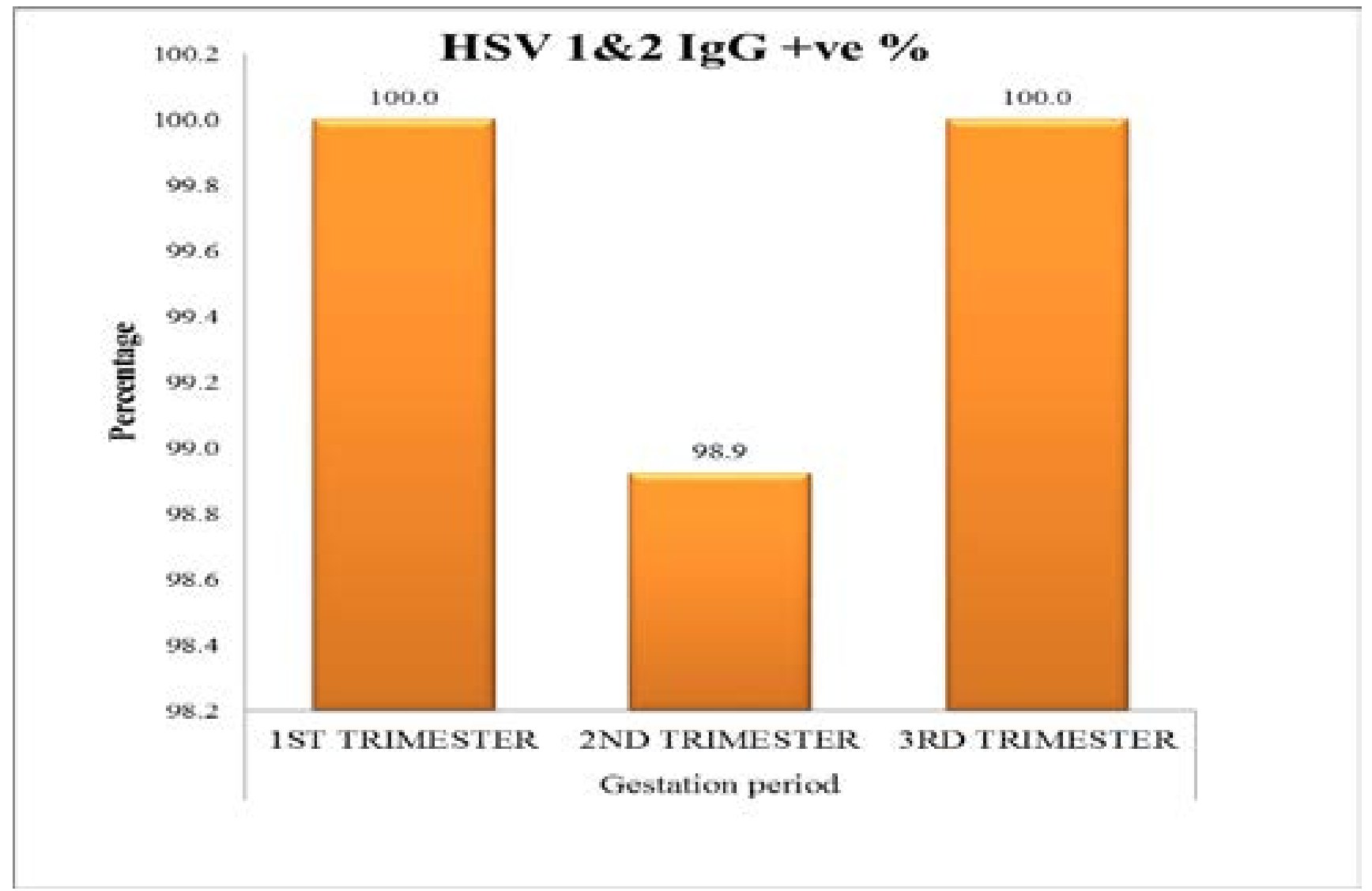

Figure 5: Gestation period related seropositivity of HSV 1\&2 IgG antibodies

\section{Discussion}

HSV-1 and HSV-2 is a frequently occurring STI, and its prevalence has rose considerably in the past two eras in several advanced and developing countries ${ }^{2,9}$. Known co-factors for HSV transmission include race, sex, age, frequency of sexual contacts, non-use of condom, duration of relationship, history of STI, duration of HSV in the source partner, HIV infection, socioeconomic status and serological outcomes ${ }^{10-13}$.

This study aimed at determining the seropositivity and determinants of anti-HSV-1 and HSV-2 IgG antibodies among pregnant women in Port Harcourt, Rivers State, South-South region of Nigeria and also to identify the demographic variables associated with the prevalence. Very high infection levels have been documented in the developing world of which Nigeria is one of them. Corey and Handsfield ${ }^{14}$ reported rates of $60-90 \%$ among gold miners and commercial sex workers respectively in South Africa. Prevalence rates ranging from 30 to $80 \%$ have been recorded among women in sub-Saharan Africa ${ }^{15}$. In Nigeria, Agabi et al. ${ }^{16}$ observed $87.0 \%$ prevalence in Jos, Nigeria. Kurewa et al. ${ }^{17}$ reported a prevalence of $51.1 \%$ among pregnant women in Zimbabwe. Though only pregnant women were used in this study, previous studies have shown that females were more prone to HSV infection than their male counterparts? Conversely, in pregnant women, the danger related with mother-child transmission of HSV has turn into a key public health concern ${ }^{9,18-19}$. Genital infection by HSV-1 and HSV-2 amongst pregnant females is a main cause for apprehension because of the danger it poses to the fetus and newborns ${ }^{18-19}$. Therefore, the assessment of HSV infection in pregnant women will help in the proper management of the infection and will also be useful for epidemiological purposes.

Anti-HSV-1 and HSV-2 IgG antibodies and its connotation with certain risk and sociodemographic factors have been previously reported. This study revealed a high seropositivity rate $(99.4 \%)$ of anti-HSV-1 and HSV-2 antibodies amongst pregnant women. HSV is most predominant among adult population; consequently ${ }^{2,9}$, several females have been exposed in advance to pregnancy ${ }^{2,9}$, eliciting the fact that most of the pregnant women have been open to each HSV-1 or HSV-2 or both that ensued in infection and formation of antibody ${ }^{2,9}$. This goes ahead to suggest a pointer of the possibility of HSV transmission amongst sexually active females ${ }^{2,9}$. This high rate is in concordance with various studies performed. 
Ghazi et al. ${ }^{20}$ detected a high seropositivity of $90.9 \%$ and $27.1 \%$ for HSV-1 and HSV-2 IgG antibodies respectively in pregnant Saudi women. Also, Sauerbrei et al. ${ }^{21}$ found $82.0 \%$ and $18 \%$ of the pregnant women seropositive for HSV-1 and -2 type specific IgG antibodies respectively. In the United States, Xu et al. ${ }^{2}$ reported a $72 \%$ overall seropositivity of HSV amongst pregnant women. The $99.4 \%$ seropositivity for HSV in this study is higher than previously reported by some other authors. It is higher than $29.08 \%$ obtained by Apurba et al. ${ }^{22}$ and $18.6 \%$ reported by Sadiq et al. ${ }^{23}$ among pregnant mothers with bad obstetric history.

The serological status of the pregnant women in the present study was compared with socio-demographic variables such as age, marital status, education, occupations and gestation period. All the variables appeared to be statistically insignificantly associated $(\mathrm{P}>0.05)$ with the prevalence of HSV IgG antibodies among the samples investigated except for marital status which was significantly associated with HSV IgG. This finding is similar to that obtained by Obeid $^{24}$ in a study among pregnant women in Saudi Arabia who observed that there was no statistically significant association between age and occupation, and HSV-1 IgG. Obeid ${ }^{24}$ also observed that education was not significantly associated with HSV-2 IgG. Another study by Rezaei-Chaparpordi et al. ${ }^{25}$ found a significant correlation between age, marital status, occupation, and HSV seroprevalence. Kurewa et al. ${ }^{17}$ also reported that the danger for a seropositive STI rises with number of lifetime sexual partners, increasing ages greater than 30 years, multigravid, polygamy, partner taking alcohol and age at sexual debut.

In previous studies, seropositivity of HSV rose steadily with age through the age range or subsequently increased above age $30^{26}$. Consequently, it drops in older females greater than 40 years of age ${ }^{26}$. However, in the present study, a total prevalence rate of $100.0 \%$ was observed in the pregnant women from ages 20-25 years, 26-30 years and 36-42 years, with a slight decrease in ages 31-35 years. A maximum number of HSV seropositivity observed in age group 26-30 years is in cognizance with a study by Apurba et al. ${ }^{22}$.

A higher prevalence was recorded among the single than married pregnant women $(100.0 \%$ versus $99.4 \%)$ which agrees with Agabi et al. ${ }^{16}$ that also found a high- er prevalence in singles compared to married individuals. This indicates that the single pregnant women included in this study should have had a greater lifetime sexual activity or have been infected in early childhood more than the married women. This results deviates from the higher prevalence rate of $71.2 \%$ observed by Rezaei-Chaparpordi et al. ${ }^{25}$ among subjects that were married than the singles in a study determining seroprevalence of HSV in Iran.

This study also showed a higher prevalence of HSV infection for pregnant women with lower educational status $(100.0 \%$ for primary, secondary and post-secondary education) than those with tertiary education. This agrees with Malkin et al. ${ }^{27}$ who found a higher HSV-1 infection in people of lower education level in France. Rezaei-Chaparpordi et al. ${ }^{25}$ also observed an increase in prevalence of HSV antibodies with a decrease in level of education. It can be deduced from the present study that a higher risk of HSV is associated with a lower level of education. This might be explained by the fact that a lower level of education was an indicator of low socioeconomic status which was a risk factor for HSV infection. Lack of proper education might give rise to ignorance of HSV acquisition and prevention. Also, enlightenment on the significance of HSV diagnosis, treatment and preventive measures might aid the control of HSV-2 transmission.

A high prevalence of HSV IgG was observed in all occupational groups. This might be explained by the fact that a lower level of occupation (unemployed in this study) was an indicator of low socioeconomic status which was a risk factor for HSV infection. This observation deviates from a high seroprevalence found in lower socioeconomic group than in high socio-economic group according to studies performed by Apurba et al. ${ }^{22}$ and Sadiq et al. ${ }^{23}$. The absence of a significant relationship found between education, occupation, and HSV seropositivity in this study compares favourably with Weiss ${ }^{15}$ who stated that educational status, socio-economic (including occupation) and religion had insignificant outcome on the seropositivity of HSV-1 and HSV-2 $2^{15}$.

A high prevalence rate was also found for pregnant women in their first and third trimester. This suggests that these groups of females were at a greater danger of 
acquiring $\mathrm{HSV}^{27}$ for instance, HSV gotten in the course of pregnancy is connected with spontaneous abortion ${ }^{27}$ which occur highest in first trimesters, and risk of neonatal transmission with highest risk occurring at third trimester. The study also showed a seronegativity of $0.6 \%$ among the pregnant women tested and is therefore at high risk and vulnerable to suffering a primary genital herpes. The danger of mother to child spread of HSV is utmost if a seronegative female acquire primary or secondary genital herpes close to the delivery, preceding to antibody development.

\section{Conclusion}

This study has confirmed the seropositivity of immunoglobulin $-\mathrm{G}(\mathrm{Ig} G)$ against HSV-1 and -2 among pregnant women. It also showed that the seropositivity of anti-HSV-1 and HSV-2 IgG antibodies among pregnant women in Port Harcourt, Nigeria is very high (99.4\%). The study also showed that age, education, occupation and gestation period were insignificantly linked to HSV IgG seropositivity. However, the seropositivity of HSV $\mathrm{IgG}$ was significantly associated with marital status. It be deduced that the risk of unborn children contracting HSV would be greater in cases where pregnant women exhibit no immunity i.e. no antibodies. From the findings of this study conducted in Port Harcourt, Nigeria, pregnant women should be educated on the risks of neonatal herpes, particularly since they are likely to have the strongest motivation for avoiding infection from partners. HSV serological testing of women should be included as a routine test during pregnancy in $\mathrm{Ni}$ geria, not only to identify those at risk of acquisition, but also to observe the prevalence rates. To the best of our knowledge, the findings of this study is the first documented seropositivity of anti-HSV-1 and HSV-2 IgG antibodies among pregnant women in Port Harcourt, Nigeria which provides a baseline data for future in-depth studies on HSV infection in South South, Nigeria.

\section{Acknowledgement}

The authors wishes to appreciate the management and staff of Braithwaite Memorial Specialist Hospital, Port Harcourt, Nigeria for their approval and assistance during this study. The exceptional technical support of Miss EM Okoli and Miss EJ Anah amongst others is also appreciated.

\section{References}

1. Brugha, R., Keersmaekers, K., and Renton A. Genital herpes infection: a review. International Journal of Epidemiology, 1997; 26: 698-709.

2. Xu, F., Sternberg, M.R., Kottiri, B.J., McQuillan, G.M., Lee, F.K., Nahmias, A.J., Berman, S.M. and Markowitz, L.E. Trends in herpes simplex virus type1 and type 2, seroprevalence in the United States. Journal of American Medical Association, 2006; 296 (8): 964-973.

3. Cusini, M., and Ghislanzoni, M. The importance of diagnosing genital herpes. Journal of Antimicrobial Chemotherapy, 2001; 47:9-16.

4. Mbopi-Keou, F.X., Robinson, N.J., Mayaud, P., Belec, L., and Brown, D. W.G. Herpes simplex virus type 2 and heterosexual spread of human immunodeficiency virus infection in developing countries: hypothesis and research priorities. Clinical Microbiology and Infectious Diseases, 2003; 9: 161-171.

5. Celum, C. L. The Interaction between Herpes Simplex Virus and Human Immunodeficiency Virus. Herpes, 2004; 1: 36A-44A.

6. Brown, Z.A., Selke, S., Zeh, J., Kopelman, J., Maslow, A., Ashley, R.L., Watts, D.H., Berry, S., Herd, M. and Corey, L. The acquisition of herpes simplex virus during pregnancy. New England Journal of Medicine, 1997; 337(8): 509-515.

7. Looker, K.L., Garnetta, G.P. and Schmid, G.P. An estimate of the global prevalence and incidence of herpes simplex virus type 2 infection. Bulletin of the World Health Organization, 2008: 86 (10): 805-812.

8. Slomka MJ. Seroepidemiology and control of genital herpes: the value of type specific antibodies to herpes simplex virus. Communicable Disease Report, 1996; volume 6, Review No. 3: R41. ISSN:1350-9349

9. Kriebs, J.M. Understanding herpes simplex virus: transmission, diagnosis, and considerations in pregnancy management. Journal of Midwifery and Womens Health, 2008; 53: 202-208.

10. Whitley, R.J. Herpes Simplex Viruses. In: Knipe DM, Howley PM, Griffin DE, et al eds. Fields Virology. 4th edition, Volume 2. New York, Lippincott, 2001; 2461-2509.

11. Stock, C., Guillén-Grima, F., de Mendoza, J.H., Marin-Fernandez, B., Aguinaga-Ontoso, I. and Krämer, A. Risk factors of herpes simplex type 1 (HSV-1) infection and lifestyle factors associated with HSV-1 manifestations. European Journal of Epidemiology, 2001; 17: 885-890. 
12. Clemens, S.A and Farhat, C.K. Seroprevalence of herpes simplex 1-2 antibodies in Brazil. Revista de Saúde Pública, 2010; 44: 726-734.

13. Stowe, R.P., Peek, M.K., Perez, N.A., Yetman, D.L., Cutchin, M.P. and Goodwin, J.S. Herpes virus reactivation and socioeconomic position: A community-based study. Journal of Epidemiology and Community Health, 2010; 64: 666-671.

14. Corey, L. and Handsfield, H.H. Gential herpes and public health: Addressing a global problem. Journal of the American Medical Association, 2000; 283: 791-794.

15. Weiss, H. Epidemiology of herpes Simplex Virus Type-2 infections in the developing world. Herpes, 2004; 11: 24A-35A.

16. Agabi, Y.A., Banwat, E.B., Mawak, J.D., Lar, P.M., Dashe, N., Dashen, M.M., Adoga, M.P., Agabi, F.Y. and Zakari, H. Seroprevalence of herpes simplex virus type- 2 among patients attending the Sexually Transmitted Infections Clinic in Jos, Nigeria. Journal of Infection in Developing Countries, 2010; 4(9): 572-575.

17. Kurewa NE; Mapingure MP; Munjoma MW; Chirenje MZ; Rusakaniko S; Stray-Pedersen B. The burden and risk factors of Sexually Transmitted Infections and Reproductive Tract Infections among pregnant women in Zimbabwe. BMC Infectious Diseases, 2010; 10:127.

18. Baker, D.A. Consequences of herpes simplex virus in pregnancy and their prevention. Current Opinion in Infectious Diseases, 2007; 20: 73-76.

19. Sauerbrei. A. and Wutzler, P. Herpes simplex and varicella-zoster virus infections during pregnancy: current concepts of prevention, diagnosis and therapy. Part 1: herpes simplex virus infections. Medical Microbiology and Immunology, 2007; 196: 89-94.

20. Ghazi, H. O., Telmesani, A. M. and Mahomed, M. F. TORCH agents in pregnant Saudi women. Medical Principles and Practice, 2002; 11(4): 180-182.
21. Sauerbrei A., Schmitt, S., Scheper, T., Brandstädt. A., Saschenbrecker, S., Motz, M., Soutschek, E. and Wutzler, P. Seroprevalence of Herpes Simplex Virus Type 1 and type 2 in Thuringia, Germany, 1999 to 2006. Eurosurveillance, 2011; (16):44, http://www.eurosurveillance.org/ViewArticle.aspx?ArticleId=20005

22. Apurba, S.S., Sandhya B.K., Senthamarai S., Sivasankari S., Kumudavathi M.S., Anitha C. and Amshavathani S.K. (2013). Serological Evaluation of Herpes Simplex Virus Type- 1/ Type- 2 Infections in Pregnant Women with Bad Obstetric History in a Tertiary Care Hospital, Kanchipuram. International Journal of $A d$ vanced Research, 2013; 1(3): 123-128.

23. Sadiq, M.S, Fatima, H., Jamil, K. and Patil, C. Study of TORCH profile in patients with bad obstetric history. Biology and Medicine, 2012; 4(2): 95-101.

24. Obeid, O.E. Prevalence of herpes simplex virus types 1 and 2 and associated sociodemographic variables in pregnant women attending king fahd hospital of the university (2007). Journal of Family and Community Medicine, 2007; 14(1): 3-7.

25. Rezaei-Chaparpordi, S., Assmar, M., Amirmozafari, N., Modiri, L., Massiha, A., Shokri-Fashtali, S., Gholizadeh, Z. and Akbari, S. Seroepidemiology of Herpes Simplex Virus Type 1 and 2 in Northern Iran. Iranian Journal of Public Health, 2012; 41(8): 75-79.

26. Smith, J.S. and Robinson, N.J. Age-specific prevalence of infection with herpes simplex virus types 2 and 1: a global review. Journal of Infectious Diseases, 2002; 186: 3-28.

27. Malkin, J.E., Morand, P., Malvy, D., Ly, T. D., Chanzy, B. De Labareyre, C., El Hasnaoui, A. and Hercberg, S. Seroprevalence of HSV-1 and HSV-2 infection in the general French population. Sexually Transmitted Infections, 2002; 78: 201-203. 